See Article page $\mathrm{XXX}$.

\section{Commentary: The right horse for the race in the repair of secondary mitral regurgitation}

\author{
Mario Castillo-Sang, MD, and Tom C. Nguyen, $\mathrm{MD}^{\mathrm{b}}$
}

In their recently published article, Okuno and colleagues ${ }^{1}$ explore surgical repair versus transcatheter edge-to-edge repair (TEER) for secondary mitral regurgitation (MR). This manuscript is timely after the 2020 American Heart Association/American College of Cardiology (AHA/ ACC) guidelines in which TEER was given a Class IIa indication in the management of severe secondary MR. ${ }^{2}$ This elegant, retrospective, propensity-matched study comparing 202 patients is the first surgical versus transcatheter repair comparison for secondary MR after the new AHA/ACC guidelines. After a 2-year follow-up, the authors found surgical restrictive annuloplasty (RA) plus coronary revascularization to be superior to TEER in reducing MR, improving ventricular ejection fraction, and reducing New York Heart Association class III-IV without a survival difference.

Favorable ventricular outcomes from RA are in part driven by surgical coronary revascularization. ${ }^{3}$ Negative ventricular remodeling from RA has been documented in animal studies, and RA has been found to be inferior to papillary muscle approximation (PMA) plus annuloplasty in retrospective and prospective randomized studies. ${ }^{3-8}$ Like the study by Okuno and colleagues, ${ }^{1}$ TEER in COAPT (Cardiovascular Outcomes Assessment of the MitraClip Percutaneous Therapy for Heart Failure Patients With Functional Mitral Regurgitation) failed to show improvements in left ventricular ejection fraction or ventricular remodeling

\footnotetext{
From the a Department of Cardiothoracic Surgery, Saint Elizabeth Healthcare, Edgewood, Ky; and ${ }^{\mathrm{b}}$ Division of Cardiothoracic Surgery, Department of Surgery, University of California San Francisco, San Francisco, Calif.

Disclosures: Dr Castillo-Sang reported speakers bureau for Edwards LifeSciences and CryoLife. Dr Nguyen reported speakers bureau for Edwards LifeSciences.

The Journal policy requires editors and reviewers to disclose conflicts of interest and to decline handling or reviewing manuscripts for which they may have a conflict of interest. The editors and reviewers of this article have no conflicts of interest.

Received for publication Aug 25, 2021; revisions received Aug 25, 2021; accepted for publication Aug 26, 2021.

Address for reprints: Mario Castillo-Sang, MD, Department of Cardiothoracic Surgery, Saint Elizabeth Healthcare, 20 Medical Village Dr, Suite 271, Edgewood, KY 41017 (E-mail: mcastillosang@gmail.com)

J Thorac Cardiovasc Surg 2021; $\mathbf{\square}: 1-2$

$0022-5223 / \$ 36.00$

Copyright (C) 2021 by The American Association for Thoracic Surgery

https://doi.org/10.1016/j.jtcvs.2021.08.059
}

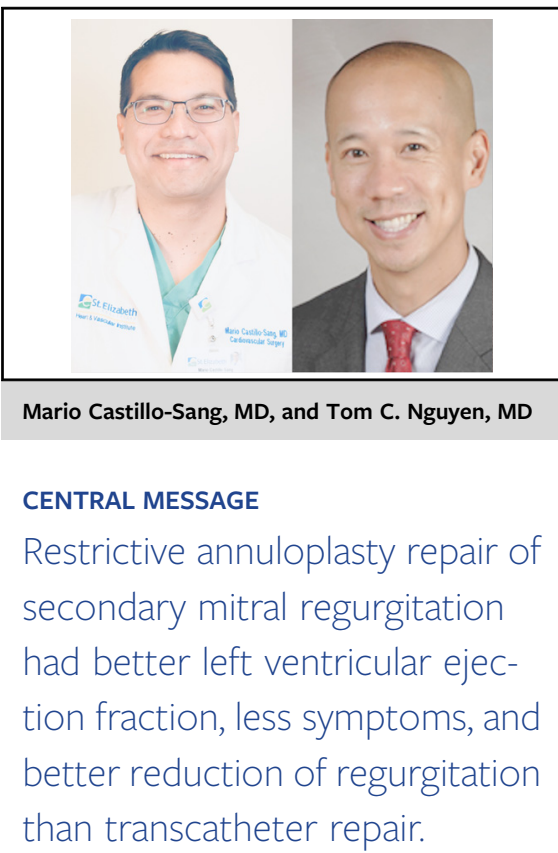

despite achieving reduction of MR, heart failure symptoms, and improving survival compared with guideline-directed medical therapy at 2 years. ${ }^{1,9,10}$

In this propensity-matched study, RA surgical repair was superior to TEER in the 2-year secondary end points, but prospective data showed RA repair alone is not universally applicable, with recurrence of moderate or worse MR of $32.6 \%$ at 1 year and $58.8 \%$ at 2 years in patients with basal aneurysms or high tenting heights. ${ }^{11-13}$ After the work by Hvass and Joudinaud, ${ }^{7}$ Nappi and colleagues ${ }^{3,8}$ compared a double-level repair (PMA) with RA and found the former to be superior in achieving ventricular remodeling with lower MR recurrence in a prospective randomized trial as it addressed the ventricular component of secondary MR.

We have learned that surgical repairs for secondary MR work best when specific valvular and ventricular features are present. We know that secondary MR is not a valvular problem but predominantly a ventricular problem and that ventricular remodeling and repair durability are better with a ventricular intervention (PMA).

So, what next? The 2020 AHA/ACC guidelines advanced and kept as $2 \mathrm{~A}$ indications TEER and surgical repair plus revascularization, respectively. Neither therapy has longterm prospective data, with surgical repair having 5-year follow-up and TEER 2-year follow-up. ${ }^{3,10}$ Okuno and colleagues $^{1}$ give us a window into this comparison, but to have a more complete picture, a prospective comparison is in order. This task will be nuanced first by the fact that 
surgical revascularization improves LV remodeling and affords longer durability of repairs, which cannot be said of percutaneous coronary intervention/stenting plus TEER. Second, double-level surgical repair may be better than RA mid- and long-term.

With all that said, where do we go from here, RA or a double-level repair with PMA? In the surgical treatment of secondary MR, we still need to understand which horse to sign up for the race.

\section{References}

1. Okuno T, Praz F, Kassar M, Biaggi P, Mihalj M, Külling M, et al. Surgical versus transcatheter repair for secondary mitral regurgitation: a propensity scorematched cohorts comparison. J Thorac Cardiovasc Surg. July 27, 2021 [Epub ahead of print].

2. Otto CM, Nishimura RA, Bonow RO, Carabello BA, Erwin JP III, Gentile F, et al. 2020 ACC/AHA guideline for the management of patients with valvular heart disease: executive summary: a report of the American College of Cardiology/ American Heart Association Joint Committee on clinical practice guidelines. $J$ Am Coll Cardiol. 2021;77:450-500.

3. Nappi F, Lusini M, Spadaccio C, Nenna A, Covino E, Acar C, et al. Papillary muscle approximation versus restrictive annuloplasty alone for severe ischemic mitral regurgitation. J Am Coll Cardiol. 2016;67:2334-46.

4. Matsuzaki K, Morita M, Hamamoto H, Noma M, Robb JD, Gillespie MJ, et al. Elimination of ischemic mitral regurgitation does not alter long-term left ventricular remodeling in the ovine model. Ann Thorac Surg. 2010;90:788-94.
5. Cheng A, Nguyen TC, Malinowski M, Liang D, Daughters GT, Ingels NB Jr, et al. Effects of undersized mitral annuloplasty on regional transmural left ventricular wall strains and wall thickening mechanisms. Circulation. 2006;114: I600-9.

6. Xu D, McBride E, Kalra K, Wong K, Guyton RA, Sarin EL, et al. Undersizing mitral annuloplasty impairs left ventricular mechanics in swine model of ischemic cardiomyopathy. J Thorac Cardiovasc Surg. November 6, 2020 [Epub ahead of print].

7. Hvass U, Joudinaud T. The papillary muscle sling for ischemic mitral regurgitation. J Thorac Cardiovasc Surg. 2010;139:418-23.

8. Nappi F, Spadaccio C, Nenna A, Lusini M, Fraldi M, Acar C, et al. Is subvalvular repair worthwhile in severe ischemic mitral regurgitation? Subanalysis of the papillary muscle approximation trial. J Thorac Cardiovasc Surg. 2017;153: 286-95.

9. Stone GW, Lindenfeld J, Abraham WT, Kar S, Lim DS, Mishell JM, et al. Transcatheter mitral-valve repair in patients with heart failure. N Engl J Med. 2018; 379:2307-18.

10. Asch FM, Grayburn PA, Siegel RJ, Kar S, Lim DS, Zaroff JG, et al. Echocardiographic outcomes after transcatheter leaflet approximation in patients with secondary mitral regurgitation: the COAPT trial. J Am Coll Cardiol. 2019;74: 2969-79.

11. Asch FM, Grayburn PA, Siegel RJ, Kar S, Lim DS, Zaroff JG, et al. Mitral-valve repair versus replacement for severe ischemic mitral regurgitation. $N$ Engl J Med. 2014;370:23-32.

12. Goldstein D, Moskowitz AJ, Gelijns AC, Ailawadi G, Parides MK, Perrault LP, et al. Two-year outcomes of surgical treatment of severe ischemic mitral regurgitation. N Engl J Med. 2016;374:344-53.

13. Ciarka A, Braun J, Delgado V, Versteegh M, Boersma E, Klautz R, et al. Predictors of mitral regurgitation recurrence in patients with heart failure undergoing mitral valve annuloplasty. Am J Cardiol. 2010;106:395-401. 